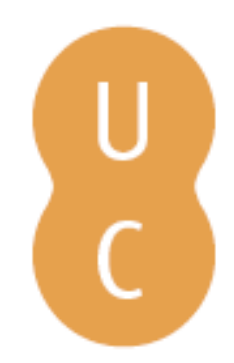

\title{
pommalina
}

\section{Gaguez e ventriloquia: a escrita criativa como prática de cidadania}

\author{
Autor(es): $\quad$ Capinha, Graça
}

Publicado por: Imprensa da Universidade de Coimbra

URL

persistente: URI:http://hdl.handle.net/10316.2/35919

DOI: $\quad$ DOI:http://dx.doi.org/10.14195/978-989-26-0690-3_8

Accessed : $\quad$ 26-Apr-2023 14:24:17

A navegação consulta e descarregamento dos títulos inseridos nas Bibliotecas Digitais UC Digitalis, UC Pombalina e UC Impactum, pressupõem a aceitação plena e sem reservas dos Termos e Condições de Uso destas Bibliotecas Digitais, disponíveis em https://digitalis.uc.pt/pt-pt/termos.

Conforme exposto nos referidos Termos e Condições de Uso, o descarregamento de títulos de acesso restrito requer uma licença válida de autorização devendo o utilizador aceder ao(s) documento(s) a partir de um endereço de IP da instituição detentora da supramencionada licença.

Ao utilizador é apenas permitido o descarregamento para uso pessoal, pelo que o emprego do(s) título(s) descarregado(s) para outro fim, designadamente comercial, carece de autorização do respetivo autor ou editor da obra.

Na medida em que todas as obras da UC Digitalis se encontram protegidas pelo Código do Direito de Autor e Direitos Conexos e demais legislação aplicável, toda a cópia, parcial ou total, deste documento, nos casos em que é legalmente admitida, deverá conter ou fazer-se acompanhar por este aviso. 


\section{O CRUZAMENTO DE SABERES NA AULA DE INGLÊS}

CONTRIBUTOS PARA UMA PRÁTICA MULTIDISCIPLINAR

ANA R. LUÍS COORD.

IMPRENSA DA UNIVERSIDADE DE COIMBRA COIMBRA UNIVERSITY PRESS 
GAGUEZ E VENTRILOQUIA：A ESCRITA CRIATIVA COMO PRÁTICA DE CIDADANIA

Graça Capinha

\section{Introdução}

A partir do desafio à prática poética através de vários exercícios de escrita criativa, este breve ensaio propõe-se levar a cabo uma reflexão sobre políticas literárias e de linguagem na sala de aula, apoiando-se em instrumentos metodológicos que emergem de conceitos como "gaguez" (Deleuze \& Guattari 1986) ou "ventriloquia" (Bernstein 1992). Trata-se de refletir sobre estratégias emancipatórias que resistem a um certo entendimento de literatura e/ou de língua e que, reportando-se ao experimentalismo poético do início do século XX, partem para uma exploração de espaços alternativos de construção de sentido. Os/as alunos/as não são aqui apenas entendidos/as como meros recetores/as de sentidos e/ ou saberes, mas também como seus/suas potenciais criadores/as. É esse desafio a uma prática de cidadania activa que, acredito, a escola deve promover.

\section{A Escrita, a Universidade e o "Real"}

Em 1997, a Faculdade de Letras da Universidade de Coimbra aprovava a criação de um Curso Livre de Escrita Criativa, que se manteve vivo, ao longo destes já mais de 15 anos, através do renovado apelo de alunos/as cujo interesse pela literatura e pelos estudos literários sempre ultrapassou a ideia da formação universitária como algo que deve ter por desígnio principal a resposta ao objetivo, hoje tão em moda, da "empregabilidade". 
Muitos/as foram os/as jovens universitários/as a recusar essa visão única da universidade como linha de montagem mercantilista, meramente destinada a produzir especialistas para manter a (re)produção de um "real" que, hoje, se vê reduzido a um único denominador comum: o do mercado (o emprego incluído). Mas, se há algo que decerto nos leva, pelo menos a alguns e algumas de nós, a rir tragicamente, é que o entendimento mais comum da atitude e/ou opção destes/as estudantes seja a crença errónea de que a literatura e o seu saber (o dos estudos literários) como o de qualquer outra arte - se destinam apenas a algumas pessoas que, por malaise e situação económica privilegiada, não querem, ou não conseguem, lidar com o mundo do "real". A esse tipo de pensamento abissal (Sousa Santos 2009), os/as que se refugiam nesse mundo "irreal e de fantasia" apresentam-se como pobres criaturas que não conseguem ter os pés na terra, podendo dedicar-se à leitura ou à escrita para se permitirem sofrer e/ou usufruir inteiramente da sua "incapacidade" ou "inadaptação". Continuamos pois a viver a separação das duas culturas e suas linguagens, mas a necessidade de uma segunda rutura epistemológica (Sousa Santos 1994) torna-se cada vez mais premente nesta nossa contemporaneidade. Trata-se de uma rutura difícil e que, em meu entender, teve início naquela segunda modernidade (Calinescu 1987) que emerge do desafio romântico - um desafio bem enraizado na realidade económica, social e política da Revolução Industrial, ao contrário daquilo que os seus epígonos nos quiseram fazer crer ao legar-nos uma literatura sobretudo de índole egocêntrica e sentimentalista (uma literatura em que a tradição portuguesa, infelizmente, continua a ser tão pródiga). A segunda modernidade ou modernidade estética, como também tem sido chamada, desafia as interpretações da primeira modernidade; ou, para ser um pouco mais rigorosa e justa, talvez deva dizer que desafia muitas das leituras erradas que desta foram feitas. Enfim, muito poderia aqui ser dito sobre a história moderna da noção de "conhecimento/ saber" (de Descartes e Hegel a Nietzsche e a Heidegger, de Newton ou Comte a Planck ou Feyerabend, de Welleck e Wimsatt a Perloff ou Quartermain - para lançar apenas alguns traços dos vários territórios em que esta discussão poderia ocorrer) mas, feliz ou infelizmente, não é nisso 
que este texto se centrará - apenas se pretendendo sublinhar que essas construções sociais do mundo, a que chamamos "real" e a que chamamos "conhecimento", não passam disso mesmo: construções sociais, que se processam na linguagem e através da linguagem. Porém, tratando-se de um material social e histórico, a linguagem não é unívoca nem monolítica, antes se criando e recriando, agonisticamente, como diversa, plural e infinitamente plena de possibilidades do excesso que ainda se encontra por articular (Lecercle 1990).

Os/as estudantes que procuram a literatura e os estudos literários e, sobremaneira, os/as que procuram lidar com os processos da criação literária propriamente dita, como acontece nessa nova/velha disciplina da escrita criativa -, longe de serem incapazes de lidar com o mundo "real" e o conhecimento meramente utilitário de um pensamento abissal, antes os pretendem pensar e questionar para, nesse ensejo, os procurarem re-form-ular (na linguagem e suas novas formas, como não poderia deixar de ser), desse modo reclamando para o presente a função social e/ou política do ato de criação poética primevo e original (Thomson 1978). Esses/as estudantes inscrevem-se, através dessa sua opção, na esteira das poéticas que optam pela escrita como um ato de cidadania, que se define pela livre abertura às possibilidades desse mesmo real (Olson 1966, Quartermain 1992). Pois, como perguntava o grande poeta modernista norte-americano Wallace Stevens (1982), se o futuro falhar (o futuro que certamente resultará de uma visão monolítica, que ainda nos domina, de modernidade e de progresso), quem nos poderá salvar? Onde estarão as alternativas?

Já Rousseau (2009), no seu Contrato Social e no dealbar do conceito de modernidade que ainda é dominante, via ser, também esse, o papel do ato poético - em que toda a comunidade se vê inscrita: quando necessário para o contrato social, há que o reformular, assim re-form-ulando o mundo, o conhecimento e/ou o pensamento, na procura de um outro devir, que não seja o da ausência de alternativas. Que isso se tenha perdido de vista e que o papel da cidadania, que é também da responsabilidade da universidade como agente fundamental para ensinar/formar para o pensamento e para o questionamento da realidade, se veja reduzido à 
“empregabilidade" é, no mínimo, pouco científico - pelos próprios preceitos da moderna e hegemónica cientificidade atual.

Digamos, então, que o primeiro objetivo da proposta de criação de um curso de escrita criativa foi, e continua a ser, acreditar que se trata, hoje mais do que nunca, de uma disciplina absolutamente crucial para cumprir os próprios desígnios da universidade como lugar de cidadania: não só lugar para a circulação do conhecimento (e que este não seja apenas aquele que, pragmática e utilitariamente, reduz o real ao que já existe) mas, sobretudo, para a criação/produção de conhecimento (o pensamento e/ou o questionamento de um real em devir). Defender a Escrita Criativa consiste, por isso e inextricavelmente, em defender o lugar e a importância não só da Literatura e dos Estudos Literários, mas também das Humanidades e de todas as Artes, na produção de conhecimento e, nesse processo, no aprofundamento da capacidade e da responsabilidade de o transformar. Recentemente publicada em Espanha, a coletânea Textos literarios y contextos escolares - La escuela en la literatura y la literatura en la escuela, organizada por Carlos Lomas, apresenta os testemunhos de grandes pedagogos/as e escritores/as espanhóis contemporâneos acerca do papel da literatura no ensino da língua e na sua formação escolar e humana, sobretudo e ainda que em tenra idade, na sua consciencialização social e política durante o período pós-guerra civil e o franquismo. Ao ler o livro, não pude deixar de perceber que muitos/as de nós, portugueses/as educados/as no período da nossa ditadura, poderíamos dar exatamente aqueles mesmos testemunhos; e penso que é urgente que o façamos, sobretudo quando vemos os estudos literários a ser praticamente eliminados da formação escolar e/ou académica.

No fundo, trata-se de defender a urgência e a necessidade de manter a abertura à alternativa - e isso tem implicações científicas e políticas (não só de política científica, mas de cidadania). Penso que foi esta urgência e esta necessidade que levaram aquele grupo de alunos/as, em 1996, a solicitar a introdução desta área na Faculdade de Letras de Coimbra e que continuaram a justificar uma procura continuada por cursos desta natureza durante todos estes anos, de tal modo que se tornou necessário criar novos cursos e novos programas numa área que, fora de Portugal, 
existe em praticamente todos os países europeus e americanos já a nível de estudos pós-graduados.

\section{A Escrita Criativa em Portugal}

Porém, nos últimos dois anos, o interesse parece vir a diminuir e afigura-se-me que isso se deve a dois fatores principais. Por um lado, a diminuição da presença da literatura nos curricula dos graus de ensino anteriores; e, por outro lado, a proliferação mercantilista de cursos de escrita criativa, largamente publicitados na internet e/ou por órgãos de poder local que, pelo menos assim, podem mostrar trabalho feito na área da cultura (de que vão certamente recolher dividendos políticos). Estes cursos são lecionados, a maior parte das vezes, por pessoas cuja única habilitação e/ou experiência para o fazer não passa da publicação de um livro de poemas ou de um romance numa editora que, nos EUA, seria chamada "V-press" ("V" de "vain" ou "vanity", ou seja, uma editora que ganha dinheiro 'com' tudo aquilo que, por desejo de protagonismo e vaidade, qualquer um/a esteja disposto/a a pagar para ver publicado/a). Contudo, e sobretudo porque não defendo critérios de leitura e/ou de qualidade literária universais e não tenho qualquer atitude elitista: mais vale ter esses cursos - que põem gente a ler e a escrever, e/ou a lidar com o fenómeno literário - do que cursos nenhuns; e muitos deles serão, certamente, excelentes. Todavia, muitas vezes tratando-se de dinheiros públicos, talvez fosse importante haver uma maior atenção aos requisitos segundo os quais estes dinheiros são gastos; e o alargamento do ensino nesta área, a nível das universidades e das outras escolas, certamente levaria a escolhas mais bem informadas, sobretudo quando se trata de ter de pagar para poder aceder a uma qualquer forma de conhecimento. Recentemente, um trabalho de investigação a nível de mestrado desenvolvido, sob minha orientação, na Universidade de Coimbra, em que se apresenta um estudo de caso na área do ensino de língua através da escrita criativa ("Esta marca que eu tenbo na língua"), levantou já alguns dados sobre esta situação no nosso país, e é sobretudo a versão unívoca 
da abordagem subjacente à maior parte dos cursos que me parece ser mais preocupante (Fonseca 2010). Esperemos que outros estudos nos permitam, em breve, vir a ter uma perspetiva mais aprofundada sobre a proliferação deste tipo de cursos no nosso país.

\section{Para um outro modelo de escrita criativa}

E passo agora à apresentação da minha própria abordagem que, como talvez já se tenha tornado evidente, parte da teorização de um grupo de pensadores/as e poetas ligados a uma escola poética norte-americana, a $L=A=N=G=U=A=G=E S c h o o l$, surgida em Nova Iorque, na década de 70. O seu principal mentor, Charles Bernstein, lecionava no Programa de Poética da Universidade de Nova Iorque, em Buffalo, durante os vários anos em que aí me desloquei para missões de investigação, tendo então a oportunidade de assistir a muitos dos seus seminários, tal como a muitos dos seminários de uma outra poeta do grupo, Susan Howe, e do próprio Robert Creeley, na altura, já um dos Papas das Letras norte-americanas. Neste modelo, a escrita é indissociável da reflexão poética e/ou política.

Falemos então de língua, que é a matéria da escrita. Começo por dizer, com Rae Armantrout, outra poeta $L=A=N=G=U=A=G=E$, que a ventriloquia é a língua-mãe (Armantrout 1991). Armantrout, tal como o vasto grupo de autores que se inscrevem nesta linha poética, tornam imediatamente clara a questão fundamental que permite o reconhecimento desta escola/ movimento (e muitos destes autores e autoras continuam a recusar esse rótulo): a questão fundamental que os reúne é a sua constatação de que, enquanto poetas - enquanto fazedores do texto -, não podem eximir-se a uma reflexão sobre o poder, isto é, não podem eximir-se a uma reflexão sobre as políticas literárias contemporâneas e, mais do que isso, a uma reflexão sobre políticas de linguagem. Reconhecendo o poder que a linguagem tem sobre nós - reconhecendo que a linguagem nos fala, e reconhecendo que aquilo a que chamamos "real" não é mais do que a uma construção social, uma ficção, que se fez hegemónica e que se naturalizou - ao poeta/à poeta cabe a responsabilidade de encontrar uma 
linguagem emancipatória, uma linguagem que recuse a "naturalidade" dessa língua-mãe que faz ventríloquos/as de todos/as nós. Para tal, a principal tarefa do/a poeta é a de se impedir de usar imagens reconhecíveis do mundo pois, ao oferecer o reconhecimento fácil dessas imagens, o/a poeta estaria apenas a legitimar a ordem desse mesmo mundo. Por isso, uma outra autora deste grupo, Lyn Hejinian, afirma que a ideologia se tornou uma linguagem lírica muito importante - que urge questionar e rever.

O problema, hoje em dia, e tal como Charles Bernstein reconhece, é que, depois de todas as descobertas científicas e tecnológicas que levaram à revisão de todas as imagens do mundo e de nós próprios; hoje, depois de reconhecermos a impossibilidade de conseguir uma totalização do sujeito ou uma qualquer totalização discursiva; hoje, depois de aceitarmos a desordem, o caos, a fragmentação - como poderemos continuar a produzir conhecimento? Como poderemos continuar a produzir sentido(s)? (Bernstein 1992) Como é possível que continuemos a ser meros ventríloquos e a repetir as mesmas imagens do mundo - como se nada tivesse acontecido? É por isto que, tenho que confessar, cada vez me espanto mais com a permanência dos modelos de representação da maior parte dos escritores do atual cânone literário de língua portuguesa.

Como reinventar as imagens do mundo que irão deslegitimar aquelas sobre as quais assenta a ordem hegemónica?

Este foi, e continua a ser, o grande desafio que as ciências e as artes do início do século XX nos deixaram. Um desafio ao qual urge - cada vez mais, como podemos perceber no atual estado a que o mundo chegou - responder. Este é o desafio que a escola $L=A=N=G=U=A=G=E$ chama a si: porque é na linguagem e através da linguagem que aquilo a que Bernstein chama "a conspurcação do espaço público" acontece - uma conspurcação que resulta, no seu dizer, das colheradas de anti-obstipante que aqueles que têm um acesso privilegiado aos media nos despejam diariamente pela goela abaixo. Mas é também na linguagem e através da linguagem que existe a possibilidade de criar estratégias - e continuo a usar a linguagem de Bernstein - de anti-absorpção e de impermeabilização (à ideologia), e de reinvenção. 
A gaguez é uma dessas estratégias de resistência à ventriloquia (Deleuze \& Guattari 1986), que nos permite (re)inventar uma linguagem emancipatória: de facto, quem gagueja não deixa de falar e/ou de produzir sentido, mas obriga-nos a prestar outra atenção às palavras proferidas. Prestando atenção a um som, a uma forma que não sai "naturalizada", damo-nos conta da linguagem como construção, num difícil processo de criação de forma/sentido. A forma chama a nossa atenção e, mais do que isso, é nas interrupções/fendas (o equivalente ao sinal "=" da palavra $L=A=N=G=U=A=G=E$ ), que se abrem, que poderemos encontrar outras possibilidades e outras alternativas ao sentido que naturalizámos como "o correto".

\section{Alguns exercícios}

E por que não usar isto mesmo para ensinar a língua?

Partindo de um título de um livro, The Years as Catches, de um outro poeta norte-americano, Robert Duncan, que foi uma das principais influências na $L=A=N=G=U=A=G=E S c h o o l$, inventei o meu primeiro exercício de escrita criativa: o "Catch". O significado da palavra é plural: apanhar; pescar; caçar; entrar no tom (quando se está num coro, por exemplo).

$\mathrm{Na}$ aula de Inglês, usaremos textos de vários/as autores/as de Língua Inglesa e poderemos ter curtos fragmentos de textos de natureza diversificada: de Shakespeare ou Chaucer a artigos de jornal ou à meteorologia; de Philip Larkin ou Auden a Hemingway ou Oscar Wilde, de discursos políticos à crítica de televisão. A ideia é aproximar o texto literário dos/ as alunos/as, democratizando a relação entre os vários usos da linguagem escrita.

Dividindo a turma a meio, vamos pedir, aos/às que ficam em pé, que leiam ininterruptamente os fragmentos (curtos), repetindo se necessário, e movendo-se por entre os/as colegas, durante cerca de 2 minutos. Aos/ às que ficam sentados/as, pedimos que tentem "apanhar/caçar/pescar" tudo o que conseguirem ouvir, criando versos - sem se preocuparem com as palavras (podem ficar apenas com sílabas) ou a sintaxe, ou "o que 
faz sentido". No final, repete-se esta parte, trocando os/as alunos/as de papel (quem leu, escreve; quem escreveu, lê).

Ao terminar esta fase, poderemos fazê-los entender algumas coisas: (1) o som tem uma materialidade - é uma matéria que não é transparente, mas, sim, opaca e difícil, que nada tem de muito natural; (2) estamos, todos os dias das nossas vidas, mergulhados/as em som, em linguagem (nas ruas, nos cafés, nas nossas relações pessoais, no computador, na TV, etc.) - e ela não aparece na forma com que a aprendemos na gramática, mas em simultâneo, sobreposta, espacializada; (3) passámos pela mesma experiência de uma criança ainda no ventre da sua mãe e nos seus primeiros meses/anos de vida - sem entender o sentido de todas aquelas vozes, que se apresentam fragmentadas e caoticamente, e de onde “apanham/caçam/pescam” som, que repetem, sem entender. É assim que todos/as entramos na linguagem e também numa outra língua: através do significante.

Fazer sentido é repetir - como os bonecos dos/as ventríloquos/as. Quando conseguimos "fazer sentido", conseguimos poder sobre aquele caos mas, atenção, apenas se esse sentido for aceitável no contexto e/ ou na comunidade em que nos encontramos (essa comunidade é a mão que faz mover a boca). E isso dá-nos prazer: somos aceites, existimos ali, sentimos que estamos em controle (mesmo sem o estar inteiramente). Antes de mais nada, para ganhar esse tipo de controle e de prazer, temos que aprender a língua.

Mas as palavras que repetimos têm também significados/conceitos que não foram criados por nós. Esses significados/conceitos já existiam na sua relação convencional e arbitrária com o significante, já estavam à nossa espera, e são o sentido do qual, doravante, estamos prisioneiros/ as - até para nos dizermos a nós próprios/as. E é aqui que o gaguejo se torna importante.

Por isso, vamos passar à leitura dos textos escritos pelos/as alunos/ as. Nessa leitura, outras coisas podem ser percebidas: (1) que há sentido a emergir da contingência das palavras (Barthes 1992) e, muitas vezes, permitindo-nos inaugurar novas metáforas e/ou novas visões do mundo; (2) que, embora os textos lidos fossem os mesmos, houve palavras que 
foram "escolhidas", por vezes, repetidamente, por alguns e algumas alunos/as e que não surgem nos poemas criados pelos/as outros/as - porque as palavras têm pesos diferentes nas nossas vidas e ouvimos/registamos mais as palavras que, por qualquer razão, mais peso tiveram nas nossas experiências sempre subjetivas (nenhuma vida é igual a outra); (3) no processo aleatório, fizemos uma escolha que não foi racional e/ou intencional, mas houve um processo inconsciente, que tem que ver com a memória individual - e é essa gaveta, esse arquivo, que se "abre" neste processo de escrita; (4) finalmente, que a inspiração assenta precisamente na memória e num qualquer evento contingente que "entra no tom" ( catch) de uma qualquer experiência individual e subjetiva - "abre-se" a memória e deixam-se fluir livremente essas palavras para a nossa escrita.

Finalmente, este exercício permitiu-nos gaguejar - chamar a atenção para a forma e a materialidade da língua, e, ao conseguirmos libertar-nos da forma como temos de a usar para fazer sentido, criámos sentidos outros e pudemos verdadeiramente assumir poder sobre a forma de dizer/ escrever o mundo. É isso que a literatura faz.

Podemos agora oferecer dois desafios: (1) reescrever o poema de acordo com aquilo que é "aceitável", ou seja, corrigir os erros de sintaxe e de ortografia, apagar sílabas ou fazer palavras a partir delas; (2) reescrever o poema de acordo com o que cada um/a considera ser o(s) seu(s) sentido(s), mesmo que isso signifique manter a opacidade da linguagem. Passando à leitura das duas possibilidades, os/as alunos/as perceberão que a segunda opção implica o risco do solipsismo, ou seja, o risco de ficar a falar sozinho/a.

Ter poder/prazer com a língua depende de quão bem a conhecemos para podermos ser nós a "manipular a nossa própria boca" e deixarmos de ser apenas bonecos de um ventríloquo. Teremos sempre que adequar o uso da língua ao contexto em que nos encontramos: para não ficarmos a falar sozinhos/as ou para resistirmos a sentidos que nos são impostos. E talvez aqui seja possível falar da necessidade de encontrar uma justiça poética: o equilíbrio entre a repetição do ventríloquo e a variação/ resistência ao sentido dominante - e de como esse equilíbrio não tem critérios universais, já que o que é repetição para mim pode ser variação 
para outro/a. Em qualquer dos casos, a plasticidade e a textura do som serão sempre o primeiro corpo a explorar.

Outro exercício poderá ser passar à utilização da repetição, procurando captar o ritmo da língua. Começar por pedir que, ao lerem o seu poema, identifiquem uma ou duas palavras cujo som se destaca. Seguidamente, pedir que repitam/escrevam essa(s) palavra(s) em sítios que considerem ser os mais importantes do poema, fazendo várias tentativas e, de cada vez, pedindo que expliquem se e como o sentido vai sendo alterado. Neste trabalho, começará a ser notória a relação tensa que existe entre palavra e silêncio - uma tensão que a poesia trabalha, nomeadamente, através do verso.

A ver ainda com a forma como a língua interfere na forma de nos dizermos e como inevitavelmente usamos a linguagem do outro, um exercício a várias mãos: passar o poema para o/a colega do lado e pedir-lhe que elimine tudo o que não considere importante em termos de significado. A seguir, devolver o texto ao autor original e pedir que reescreva o texto, agora limitado pelo colega, com menos palavras e menos sentidos. Dizer-se depende das palavras/sentidos à nossa disposição - e é a comunidade que nos oferece (ou não) esse material. Somos seres transdiscursivos e transindividuais (Foucault 1992), sempre em processo, sempre em ato de fala. Esta é uma boa forma de questionar o entendimento dominante do/a autor/a como indívíduo auto-suficiente, um génio absolutamente original - um entendimento que herdámos de um certo epigonismo romântico e/ou burguês.

\section{Notas finais}

Estes são apenas alguns dos exercícios possíveis para ativar o potencial criativo dos/as alunos/as, procurando que a aprendizagem se desenrole de forma participativa. A luta com a plasticidade e a textura do som evita o medo que a maior parte dos/as alunos/as tem do que considera ser "abstração". Neste jogo com o som e as representações, toma-se consciência da materialidade e do artifício que a linguagem significa, e do 
poder que sobre ela se pode conseguir se a conhecermos de forma cada vez mais aprofundada. Joga-se com a correção e a incorreção a partir de diferentes perspetivas, permitindo, simultaneamente, que os/as alunos/as vão tomando consciência de outras dimensões que, sendo estéticas, são, de igual modo, dimensões sociais e políticas. No prazer desse jogo se cria o sentido de ação e de participação - na língua e através da língua. Aí se inaugura o sentido da cidadania.

\section{Referências}

Armantrout, Rae. 1991. Necromance. Los Angeles: Sun \& Moon Press.

BARTHES, Roland. 1981. O Grau Zero da Escrita seguido de Elementos de Semiologia. Lisboa: Edições 70.

Bernstein, Charles. 1992. A Poetics. Cambridge: Harvard University Press.

Calinescu, Matei. 1987. Five Faces of Modernity: Modernism, Avant-garde, Decadence, Kitsch, Postmodernism. Durham: Duke University Press.

Deleuze, Gilles e GuatTARI, Felix. 1986. Kafka: Toward a Minor Literature. Minneapolis: The University of Minnesota Press.

Duncan, Robert. 1966. The Years as Catches. Berkeley: Oyez.

Fonseca, Teresa Margarida Ferreira. 2010. 'Essa Marca que Eu Tenho na Língua'. O Papel da Escrita Criativa na Reinserção Social: Um Estudo de Caso. Dissertação de Mestrado em Estudos Anglo-Americanos. Coimbra: Faculdade de Letras da Universidade de Coimbra.

Foucault, Michel. O que é um autor?. Lisboa: Vega, 1992.

Hejinian, Lyn. 2000. The Language of Inquiry. Berkeley: University of California Press.

LECERCLE, Jean-Jacques. 1990. The Violence of Language. London: Routledge.

LOMAS, Carlos. Org. 2008. Textos literarios y contextos escolares - La escuela en la literatura y la literatura en la escuela. Barcelona: Graó.

Olson, Charles. 1966. Projective Verse. In Selected Writings. New York: New Directions.

Quartermain, Peter. 1992. Disjunctive Poetics. From Gertrude Stein and Louis Zukofsky to Susan Howe. Cambridge: Cambridge University Press. 
Rousseau, Jean-Jacques. 2009. Contrato Social. Lisboa: Círculo de Leitores.

SAntos, Boaventura de Sousa. 2009. Para além do Pensamento Abissal: Das linhas globais a uma ecologia de saberes. In Boaventura de Sousa Santos e Maria Paula Meneses. Orgs. Epistemologias do Sul. Coimbra: Almedina.

SAntos, Boaventura de Sousa. 1994. Pela Mão de Alice: O Social e o Político na Pós-Modernidade. Porto: Afrontamento.

STEvens, Wallace. 1982. Owl's Clover. In Wallace Stevens. Opus Posthumous. New York: Vintage Books.

Thomson, Denys. 1978. The Uses of Poetry. London: Cambridge University Press. 